\title{
CONCEPÇÕES PARA O ENSINO DA TÁTICA E DA TÉCNICA DAS MODALIDADES
} COLETIVAS NA ESCOLA

Ensino do esporte na escola

${ }^{1}$ Romulo José Cesar Lins; ${ }^{2}$ Fabiano Sousa

\section{RESUMO}

Introdução: $O$ trabalho surge a partir da apreensão acerca do ensino do esporte, em especial os coletivos de invasão, nas aulas de Educação Física Escolar. Objetivo: No trabalho corrente propõese, subsidiados em alguns estudos e autores, uma maneira de trabalhá-los através de situações ativas de ensino, sem desconstruir a essência do esporte propriamente dito. Método: $O$ artigo caracteriza-se numa pesquisa qualitativa, baseada em interpretações, no sentido de progredir em um processo indutivo de desenvolvimento de hipóteses e teoria à medida que se aprofunda o estudo. Conclusão: Através dos Métodos Situacional, TGfU e MED, com suas abordagens e elementos teóricos, cremos na possibilidade de reafirmar as constituintes táticas e técnicas das modalidades esportivas de invasão nas aulas de Educação Física.

Palavras-Chave: Esporte Coletivo, Educação Física, Ensino da Tática e Técnica, Métodos de ensino.

1 Pós-Graduado pela Universidade de Pernambuco. ${ }^{2}$ Docente no Curso de Educação Física da Universidade Salgado Oliveira.

Email: 1romulocanhoto@hotmail.com; 2fabianotcs@gmail.com

\section{CONCEPTIONS FOR TEACHING THE TACTICS AND TECHNIQUES OF COLLECTIVE MODALITIES IN SCHOOL}

\section{ABSTRACT}

Introduction: The work arises from the apprehension about the teaching of sport, especially the collective invasion, in the school physical education classes. Objective: The current work proposes, subsidised in some studies and authors, a way to work them through active teaching situations, without deconstructing the essence of the sport itself. Method: The article is characterized in a qualitative research, based on interpretations, in order to progress in an inductive process of development of hypotheses and theory as the study deepens. Conclusion: Through situational methods, TGfU and MED, with their approaches and theoretical elements, we believe in the possibility of reaffirming the tactical and technical constituents of the sports invasion modalities in physical education classes.

Keywords: Collective Sport, Tactical and Technical Teaching, Teaching methods.

\footnotetext{
1 Pós-Graduado pela Universidade de Pernambuco. ${ }^{2}$ Docente no Curso de Educação Física da Universidade Salgado Oliveira.

Email: 1romulocanhoto@hotmail.com; 2fabianotcs@gmail.com
} 


\section{INTRODUÇÃO}

O presente ensaio surge a partir da apreensão acerca do ensino do esporte, em especial os esportes coletivos de invasão, nas aulas de Educação Física Escolar (EFE).

A fim de nortear a produção e julgando ser necessário trazer contribuições referente à Educação Física, enquanto prática pedagógica e propriedade da escola, se tentou conceituála mesmo sabendo que defini-la não seria uma tarefa simples. Surgem várias questões sobre qual seu papel, sua finalidade, sob quais argumentos ela mantém-se efetiva no currículo escolar.

Para o Coletivo de Autores (1992), várias são as denominações desta prática, mas que ainda são irrelevantes, uma vez que não conseguem mudar o ensino conservador existente. Os autores deixam como conceito provisório de Educação Física, uma atividade guiada por uma "prática pedagógica que, no âmbito escolar, tematiza formas de atividades expressivas corporais configurando o que eles chamam de cultura corporal" (p.50).

Noutra perspectiva, Freire (2009), defende uma Educação Física pautada na construção do conhecimento através do corpo. Acreditando que a Educação Física deve promover o desenvolvimento motor e mental da criança, visto que tal prática é "educação de corpo inteiro, entendendo-se, por isso, (...) que educar corporalmente uma pessoa não significa provê-la de movimentos qualitativamente melhores, apenas." (p. 77).

Acreditamos que o propósito da Educação Física Escolar, em qualquer que seja a frente de pensamento pedagógico, é de oportunizar uma prática gerida por expressões corporais nas quais sejam identificadas e vivenciadas situações de reflexão, busca pela autonomia, saúde e lazer por parte do aluno, além de, obviamente, proporcionar contribuições no sentido de formação e aprendizagem. Afinal, a disciplina enquanto "propriedade" da escola, também tem a obrigação explícita do desenvolvimento.

Reafirmando os propósitos específicos da Educação Física na escola, reconhecemos a existência de uma relação que parte do conhecimento corporal e das suas variadas formas de expressão cultural, almejando que o aluno possua um conhecimento organizado a respeito da cultura humana de movimento (DAÓLIO, 1996), posto que "estamos tratando de um universo em que os atos motores são indispensáveis, não só na relação com o mundo, mas também na compreensão dessas relações" (FREIRE, 2009, p. 75)

Assim, no sentido cultural do movimento, o fenômeno esportivo tem sido historicamente escolarizado, a fim de propor aos alunos, um construto social para o meio social. Quer-se com isso dizer que o esporte, enquanto produto simbólico das representações humanas, ganha validade $e$ necessidade de apropriação nos ambientes de formação pedagógica.

Para o alcance de tal, estudo corrente propõe estratégias, com referência em métodos de ensino que enfatizam processos interativos, no estabelecimento de relações entre o aluno, o meio e as tarefas.

\section{MÉTODO}

O trabalho caracteriza-se numa pesquisa qualitativa, que segundo Thomas (2007), é baseado em interpretações, no sentido de progredir em um processo indutivo de desenvolvimento de hipóteses e teoria à medida que se aprofunda o estudo, onde procurou entender as possibilidades de ensino dos componentes específicos e essenciais das Modalidades Esportivas Coletivas - MEC -, através de concepções ativas de ensino, nas aulas de Educação Física Escolar.

A produção está centrada na Pesquisa Bibliográfica que usufruiu de informações disponíveis em livros, monografias e dissertações acerca dos temas pedagogia do esporte, iniciação esportiva e esportes coletivos na Educação Física, para se ter um maior embasamento teórico a respeito do conteúdo esporte coletivo, nas aulas de Educação Física.

\section{IDENTIFICAÇÃO DOS CONTEÚDOS}

Dentre as categorias e formatos encontrados na classe esportiva, direcionamos o nosso foco de estudo para as MEC, que se constituem, sem dúvidas, como os conteúdos mais vivenciados e discutidos na Educação Física Escolar.

Para Garganta (1998), tais modalidades caracterizam-se pelo confronto entre duas equipes que se dispõem pelo terreno de jogo e se movimentam de forma particular, com 0 objetivo de vencer, alternando-se em situações de ataque e defesa. Nesse sentido, se cria a relação de cooperação e oposição, onde "cada princípio de ataque encontra oposição num princípio de defesa" (Quadro 01) (De ROSE JUNIOR, 2005, p.73). 
Tabela 01 Princípios operacionais das MEC (Adaptado de BAYER, apud DE ROSE JUNIOR, 2005).

\begin{tabular}{lll}
\hline \multicolumn{1}{c}{ ATAQUE } & \multicolumn{1}{c}{ DEFESA } \\
\hline - Conservação da bola & Recuperação da bola \\
bola até a meta contrária & $\bullet$ & $\begin{array}{l}\text { Impedir/dificultar a progressão dos } \\
\text { jogadores e/ou da bola até minha } \\
\text { meta }\end{array}$ \\
\hline
\end{tabular}

- Atacar a meta

- Defender a meta

Silva e Júnior (apud GRECO et al., 2010, p.04) dizem que "as modalidades esportivas coletivas são caracterizadas por ações de caráter aleatório, imprevisível e variável", de forma que há "um conflito na qual a superação é o objetivo essencial" (GARGANTA, 1996, p. 07).

E nas particularidades das MEC, o uso das habilidades motoras, captação de informações e da tomada de decisão são de reconhecida importância, levando em conta a necessidade de saber se adaptar as imprevisibilidades da prática esportiva. Devido a isso, o conhecimento e apropriação das constituintes táticas e técnicas, é fundamental no processo de aprendizagem nas aulas de Educação Física Escolar (SCAGLIA et al., (2007, p. 176).

$\mathrm{Na}$ aula de Educação Física, os aspectos táticos e técnicos das MEC, se tratados de maneira lúdica e descontraída, centram toda a experiência na própria criança e estima-se uma possibilidade de construção em conjunto. Aparece a oportunidade de aprender a cooperar, relacionar-se com 0 outro através da empatia e de relações interpessoais, exercitar a tolerância, respeitar as diferenças. Porém é preciso analisar se essas constituintes estão sendo transmitidas, enquanto conteúdo pedagógico da escola.

\section{ABORDAGEM TÁTICA E TÉCNICA}

A fim de superar as tendências tradicionais-tecnicistas de transposição esportiva, o princípio tático do esporte ganha maior evidência e investimento nos processos de ensino. Cortez (2006) defende que tática é - "processo onde se conjugam todas as possibilidades físicas, técnicas, teóricas, psicológicas e cognitivas, para dar uma solução imediata às inúmeras situações imprevistas que são criadas em situação de oposição". A necessidade da orientação tática é o que movimenta o sentido de aprendizagem esportiva, pois não há lógica na apropriação do "como fazer" (técnica), sem antes não nos ter sido apresentado "o que fazer" (tática).

Dessa forma, a tática é a utilização adequada e racional da técnica, ou seja, fundamentos individuais de ataque e defesa, aplicados numa situação de jogo. (BIANCO, 2006)

Greco (1997) alega que as exigências táticas têm como objetivo fazer com que os alunos aprendam a tomar decisões e resolver problemas que ocorrem durante o processo. Para o autor, a tomada de decisão pode ser interpretada como a disposição em resolver as situações que o momento do jogo proporciona. Entende-se por isso, que a dimensão tática adquire seu nível de expressão mais alto no contexto das modalidades coletivas.

Concordamos com o autor, posto que, a imprevisibilidade do jogo, exige um constante ajuste espacial e temporal do indivíduo, para o alcance das metas (SCAGLIA, 2009, p. 153).

Mas, segundo De Rose Junior (2005), se tem evitado a abordagem tática com crianças, devido a uma má conceituação da constituinte, transformando-a em sinônimo de estratégia. $\mathrm{O}$ autor justifica que:

"muitas vezes crianças precocemente envolvidas em competições e que são cobradas por seus professores/técnicos a executar "jogadas" e/ou manter determinados comportamentos estratégicos. Tudo isso pode ter como resultado a formação de atletas que utilizam movimentos estereotipados e encontram dificuldades em aplicar a técnica para resolver situações-problema que lhes são impostas pelas modalidades esportivas coletivas" (DE ROSE JUNIOR, 2005, p. 02).

Partindo para a análise conceitual da técnica, Greco (2007) a define como a "interpretação no tempo-espaço e situação do meio instrumental operativo necessária à resolução e execução da tarefa ou problema que enfrenta no esporte" (p. 55).

Para Bianco (2006), o conceito de técnica assemelha-se ao conceito de habilidade, podendo ser compreendida como os fundamentos específicos e gerais que os praticantes executam dentro da modalidade esportiva que praticam.

As valências técnicas, quando vivenciadas na Educação Física Escolar, entre outros aspectos devem estimular que o aluno ocupe uma posição central, sendo considerado o construtor ativo das suas próprias atividades (BIANCO, 2006). 


\section{Ensino do Esporte na Escola}

Sob essas condições, a utilização de abordagens tradicionais no trato das componentes técnicas esportivas, perde espaço no contexto educacional, uma vez que a ruptura do esporte em partes reduz o aprendizado e o desenvolvimento do conteúdo, "enquanto atividade que se busca a tomada de decisão e a compreensão das situações-problema" (BIANCO, 2006, p. 25), não possibilitando o exercício da reflexão e autonomia.

Em estudo relativo à técnica esportiva como conhecimento nas aulas de Educação Física, Rodrigues et al., (2008) afirma que:

“as técnicas devem ser compreendidas como um patrimônio a ser transmitido aos alunos, pois são movimentos construídos historicamente".

Com essa justificativa, o autor, em um sentido crítico, legitima a condição das constituintes técnicas na EFE, fortalecendo-a enquanto conteúdo e necessidade da aprendizagem do esporte.

Pensando na concretização da aplicabilidade do esporte nas aulas de Educação Física, Mesquita (apud NASCIMENTO, 2004) assegura que:

"Para que ocorra a transposição das habilidades técnicas para o jogo, o aluno deve vivenciar, desde o início da aprendizagem, algumas progressões que evidenciem as situações de jogo. As tarefas devem ser realizadas de forma que integrem a estrutura e funcionalidade do jogo, dando sentido à aprendizagem. As habilidades técnicas estariam condicionadas às características do jogo" (p. 51).

Dessa forma, é impreterível que a aprendizagem de uma constituinte técnica venha pela totalidade do esporte, ou seja, é necessário que haja uma integração com os elementos táticos, tornando possível o desenvolvimento dos aspectos psicológicos e cognitivos dos alunos (BIANCO, 2006).

\section{RESULTADOS E DISCUSSÃO}

A escolha metodológica de um professor para o desenvolvimento de sua aula é o eixo principal para o sucesso dela. $O$ método deve proporcionar aos alunos as melhores oportunidades para a aprendizagem do conteúdo (GRECO, 2007).

No sentido das especificidades dos métodos de ensino para os esportes coletivos, Bayer (1994) apresenta uma classificação destes em Métodos Tradicionais e Ativos, reconhecendo-os como grandes e opostas correntes pedagógicas. Para Caldas et al., (2014), os Métodos Tradicionais baseiam-se no princípio da simplicidade, análise $e$ progressão. Repetição e memorização são os pilares dessa concepção. Já os Métodos Ativos, centram as experiências na vivência, iniciativa e reflexão do praticante.

Defensores críticos dos Métodos Ativos de ensino, Mesquita \& Graça (2006) veem uma possibilidade de melhora cognitiva e motora dos alunos, pois neste plano metodológico, é atribuído ao aluno o desenvolvimento das experiências de aprendizagem. "Este paradigma da aprendizagem faz o professor descentrar-se de si próprio para se situar no aluno (...), no sentido de criar a melhor atmosfera da aprendizagem" (p.270).

No trabalho corrente propõe-se, subsidiados em alguns estudos e autores, uma maneira de trabalhar os esportes coletivos através de situações de ensino, sem desconstruir a essência ou negar o direito de apropriação do esporte propriamente dito, mas capaz de possibilitar experiências em movimentos esportivos, independente do talento de cada aluno (KUNZ, 1994).

Queremos afirmar que o professor de Educação Física tem o compromisso em fornecer o conhecimento esportivo, e entendemos como forma ideal, uma transmissão que dê o direito do aluno entendê-lo numa esfera totalitária, de forma que 0 apoderamento de suas componentes táticas e técnicas permita o desenvolvimento de uma consciência corporal, garantindo a preservação do significado cultural do esporte.

Dessa forma surgem os princípios norteadores dos métodos de ensino de Iniciação Esportiva e Educação Física Escolar. Greco (2007) identifica o princípio AnalíticoSintético, o Parcial-Global e o Situacional como as frentes históricas que regem a iniciação esportiva e EFE no Brasil (Quadro 01). 
Quadro 01 Métodos de ensino na EFE e iniciação esportiva (adaptado de Greco, 2007)

\section{ANALITICO-SINTÉTICO PARCIAL-GLOBAL SITUACIONAL}

Processo realizado em Intenção de adequar a Ações básicas extraídas de

partes, apresentando uma complexidade do jogo situações padrões de jogo;

divisão dos gestos, das esportivo através de uma

técnicas, da ação motora em sequencia de jogos

mínimos detalhes;

recreativos acessíveis á faixa

Estas situações de jogo

$O$ aluno conhece em primeiro etária e a capacidade técnica lugar os componentes do iniciante.

podem, às vezes, não

abranger a ideia total do jogo porém, apresentam o

técnicos do jogo através de

elemento central do mesmo;

repetição de exercícios que

são acoplados a séries de

exercícios;

Automatização dos gestos

Apresentação do jogo em diferentes estruturas

técnicos e táticos;

Exercícios do "mais simples"

ao "mais complexo".

Graça \& Mesquita (2007) enaltecem os métodos TGfU (sigla em inglês para "modelo de ensino para jogos de compreensão") e MED (Modelo de Educação Desportiva"), alegando que estes, em concordância com suas implicações filosóficas, possibilitam ao aluno uma aprendizagem técnico-tática através de jogos reduzidos e da contextualização das situações de jogo.

O TGfU inicialmente apresentado por Bunker e Thorpe (1982), ganhou evidência através das publicações de autores da pedagogia do esporte, se fazendo acreditar que sua estruturação permite que o praticante tenha uma compreensão lógica do jogo, tornando-o mais inteligente $e$ eficiente, em um sentido esportivo.

"O modelo de ensino dos jogos para a compreensão propõe uma porta de entrada diferente da tradicional via da técnica, a porta da compreensão do jogo, da apreciação dos elementos que fazem dele o jogo que é" (MESQUITA \& GRAÇA, 2006 p. 272). Ainda para os autores, essa esfera metodológica transcende a ideia de tornar o aluno pessoa ativa no processo de aprendizagem, a partir do momento em que há o enfrentamento dos problemas do jogo, fazendo-o tomar, decidir e avaliar suas próprias decisões. 



\section{Ensino do Esporte na Escola}

Figura 01 - Processo de ensino pela compreensão tática (BUNKER \& THORPE, apud GRECO, 2009; MESQUITA \& GRACCA, 2006).

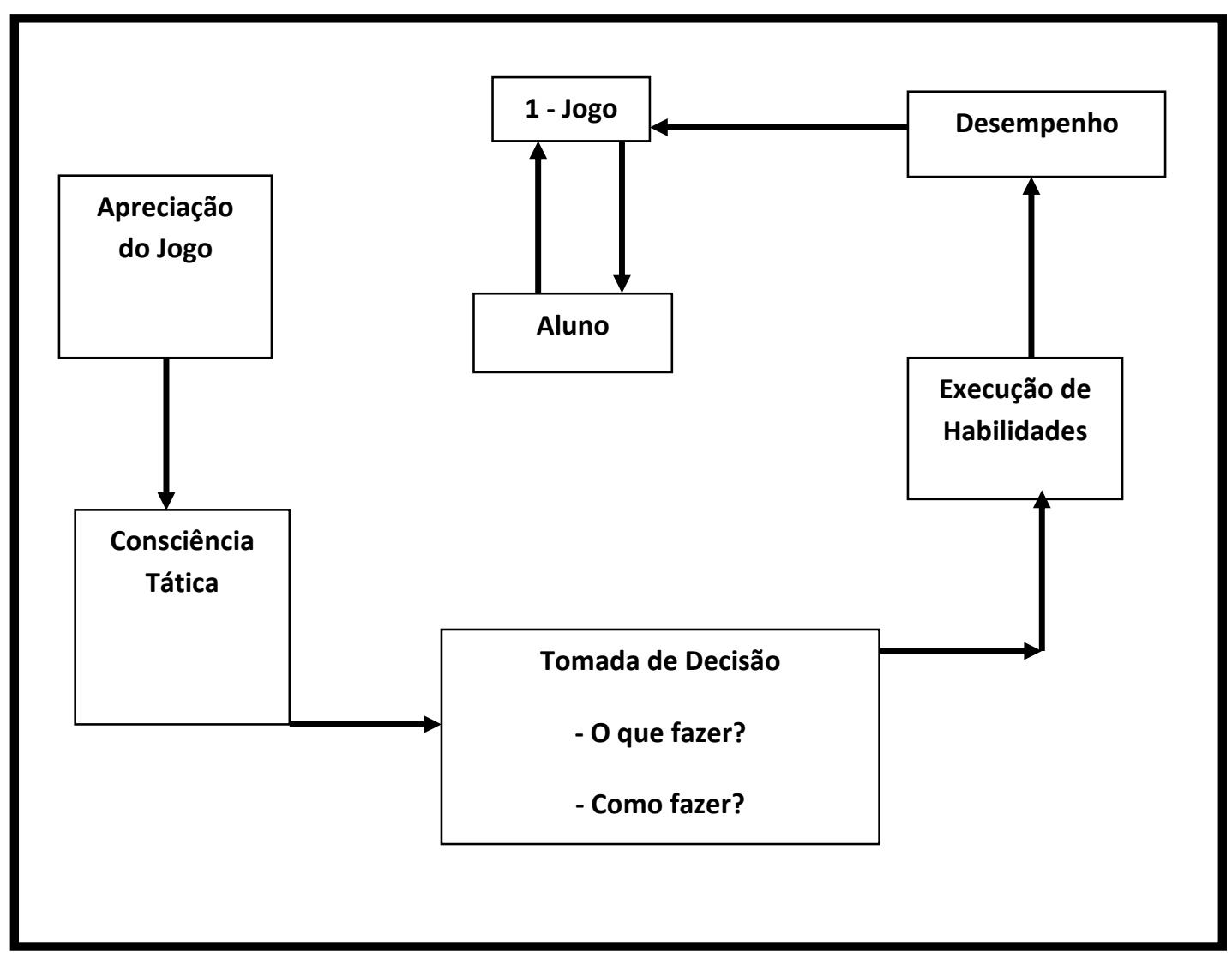




\section{Ensino do Esporte na Escola}

Sadi et al., (2008) no que concerne à relação esporte-jogo, dizem que:

"O esporte é um produto cultural que surge do jogo e, somente quando institucionalizado, é assim intitulado. Desta forma, todo esporte se origina de um jogo e, dessa perspectiva, é fácil compreender a utilização dos jogos como elementos metodológicos para o ensino do esporte (p. 17).

Balbino (apud SCAGLIA, 2009, p. 143), diz ser "necessário compreender o jogo como elemento fundamental do esporte, bem como sua essencial conexão com o sentido de jogar".

Scaglia (2009, p. 201) também menciona a ligação entre jogo e esporte, quando diz que "se confundem um com o outro, pois ambos possuem a mesma natureza, o sentido literal e dinâmico do jogar. Assim, o principio sobre qualquer forma de abordagem aos jogos coletivos deverá começar na sua forma primária de jogo".

Ainda com Scaglia (2009), em sua elaboração metodológica para o ensino das MEC na Educação Física Escolar, apoia-se em Freire (1994), no sentido de validar a abordagem interacionista, "no qual o conhecimento é permitido por meio de desafios adequados e oportunos aos alunos, segundo suas fases de desenvolvimento" ( $p$.
60). Diante desta necessidade, o jogo obtém pressupostos, pois proporciona ao aluno a possibilidade de aprender, através da exploração da conduta motora e competência interpretativa.

Acredita-se que o jogo, suas formas e aplicações, oferecem ao praticante diversas ações desafiadoras, promovendo novas dificuldades e assim potencializando habilidades técnicas necessárias ao andamento do próprio jogo e a tomada de decisão (VENDITTI et al., 2008),

As palavras dos autores acima concordam com as de outros autores (GRECO, 2007; BIANCO, 2006; GARGANTA, 1995); quando apontam que, para que haja um entendimento $e$ aprendizagem maior do esporte, algumas alterações nas estruturas do jogo podem ser feitas, tentando contribuir para seu melhor entendimento. Na concepção de Scaglia (2009), o jogo é compreendido por uma série de estruturas comuns, com uma lógica interna, determinando 0 seu desenvolvimento. Aparece a necessidade de identificar as variáveis estruturais do jogo.

Gimenez (apud BIANCO, 2006) define cinco variáveis estruturais que podem orientar a modificação do jogo, e a possibilidade de criação de diferentes tipos de jogos (Quadro 02).

Quadro 02 - Variáveis estruturais dos jogos que podem ser manipuladas para criação de diferentes tipos de jogos (adaptado de Gimenez, apud Bianco, 2006)

\begin{tabular}{|c|c|}
\hline ESPAÇO & $\begin{array}{l}\text { - } \quad \text { Alterar a dimensão do jogo; } \\
\text { - } \quad \text { Alterar a dimensão, a forma ou o número de cestos ou balizas; } \\
\text { - } \quad \text { Restringir áreas jogáveis; } \\
\text { - } \quad \text { Obrigar jogadores a mudar as posições que ocupam durante o jogo; } \\
\text { - } \quad \text { Obrigar os jogadores a manter uma distância determinada uns dos outros. }\end{array}$ \\
\hline TEMPO & $\begin{array}{l}\text { - } \quad \text { Limitar o tempo para realização de determinadas ações; } \\
\text { - } \quad \text { Limitar o tempo de permanência em determinadas áreas ou zonas; } \\
\text { - } \quad \text { Determinar a passividade se não jogar num ritmo imposto; } \\
\text { - } \quad \text { Acelerar/desacelerar o ritmo do jogo; } \\
\text { - } \quad \text { Alterar o número de períodos de descanso ou de jogo. }\end{array}$ \\
\hline REGRAS & $\begin{array}{l}\text { - } \quad \text { Variar o sistema de pontuação; } \\
\text { - } \quad \text { Eliminar algumas regras que ainda não sejam compreendidas; } \\
\text { - Introduzir novas regras; }\end{array}$ \\
\hline TÉCNICA & $\begin{array}{l}\text { - } \quad \text { Modificar número, forma, tamanho, ou composição da bola; } \\
\text { - } \quad \text { Determinar o №. e a forma de contatos com a bola; } \\
\text { - } \quad \text { Organizar situações que condicionem o uso de determinadas técnicas. }\end{array}$ \\
\hline TÁTICA & $\begin{array}{l}\text { - } \quad \text { Variar o número de jogadores (igualdade ou desigualdade numérica); } \\
\text { - } \quad \text { Determinar a função de alguns jogadores; } \\
\text { - } \quad \text { Estabelecer um sistema de jogo em ataque e/ou defesa; } \\
\text { - Estabelecer as mudanças dos sistemas de jogo frente a determinadas } \\
\text { circunstâncias. }\end{array}$ \\
\hline
\end{tabular}




\section{Ensino do Esporte na Escola}

Ressaltamos que estas estruturas, foram aqui apresentadas separadamente, para uma melhor compreensão das informações, uma vez que "o jogo não se reduz a partes isoladas e, quando o faz dessa forma, perde seu contexto funcional sistêmico, organizacional, de imprevisibilidade, de cooperação, de autorregulação" (SCAGLIA, 2009, p. 61)

As concepções ativas de ensino aqui citadas, abordadas na EFE, podem proporcionar efeitos relevantes para 0 desenvolvimento do aluno, no sentido da aprendizagem das MEC. Trabalhar os esportes coletivos em um formato de jogo criaria um ambiente favorável ao processo de ensino-aprendizagem, decorrente de uma possível entrega do jogador ao desejo de jogar (SCAGLIA, 2009). Entre outros fatores, a tomada de decisão, a percepção e a antecipação tendem a ser refinadas, através destas ferramentas metodológicas.

Nessa perspectiva, visualizamos o jogo enquanto eixo de materialização de formação e instrumento de aprendizagem das modalidades coletivas nas aulas de Educação Física Escolar, uma vez que o sentido do jogo, quando priorizado, traz consequências no desenvolvimento da

capacidade de jogo ${ }^{1}$, concretizando o "deixar-se descobrir" através do "deixar jogar" (GRECO, 2007).

\section{CONCLUSÃO}

Os esportes coletivos quando evidenciados nas aulas desta disciplina devem ser compreendidos enquanto conteúdo didático agregado ao citado currículo escolar, pois também se trata de um processo sistematizado e planejado pelo professor.

O estudo implementou um conteúdo temático da Educação Física Escolar, com referência em métodos de ensino que enfatizam processos interativos, no estabelecimento de relações entre o aluno, o meio e as tarefas.

Buscou-se neste trabalho, apresentar algumas possibilidades de intervenção pedagógica para o trato e conhecimento das MEC, como também mostrar a importância

\footnotetext{
1 Interação do desenvolvimento das diferentes capacidades que compõem o esporte em uma situação de jogo (Greco, 2007)
}

destas, na construção de uma consciência esportiva. Vale ressaltar que a aula de Educação Física é uma prática voltada à formação do aluno e deve ter obrigatoriedade educativa, fazendo com que o processo de ensino das Modalidades Esportivas, seja um momento de aquisição de conhecimento, a partir da exploração dos seus princípios (das MEC).

Assim, os Métodos Ativos de ensino das MEC apresentam qualidades essenciais para a atual perspectiva de prática pedagógica da Educação Física, pois abordam uma proposta em que o ato de jogar configura-se como principal alicerce norteador de desenvolvimento de tais competências.

Diante dessa abrangência do jogo, acredita-se que o aluno possa desenvolver uma inteligência tática para 0 esporte coletivo, já que incessantes inquietações surgirão (o que fazer? Quando fazer?) com o ato de jogar. Desse modo as constituintes técnicas também despertariam. Eclodiriam como mecanismos de respostas às situações do jogo, sendo utilizadas em acordo com as necessidades do momento.

O jogo enquanto dimensão complexa e fenômeno condicionante das MEC, com suas alterações e imprevisibilidades, pode colaborar na fixação dos conteúdos esportivos vivenciados pelas crianças, pois o prazer trazido pelo jogo faz com que as práticas sejam rememoradas na perspectiva de revivenciar as sensações. Mas, creditamos ao professor manter a chama esportiva do aluno acesa, por meio de abordagens e métodos que intensifiquem 0 entusiasmo decorrente da prática do jogo esportivo.

Encara-se como competência do professor, ter a capacidade de modificar as possibilidades de jogos, gerando constantes desafios, sem desrespeitar os limites (físicos, psicológicos, cognitivos) dos alunos. Faz-se necessário, um tratamento didático em um esquema sequencial, ao longo dos anos escolares, de forma que os conteúdos possam ser compreendidos e validados ao término da educação básica.

Dessa forma elevaríamos a qualidade de ensino e aprendizagem das modalidades coletivas de invasão, nas aulas de Educação Física. Subsidiaríamos a vivência esportiva abordando a situação do jogo, repleta de elementos que possibilitam a ação e reflexão do aluno. 



\section{REFERÊNCIAS}

AUTORES, C.. Metodologia do ensino de Educação Física. São Paulo. Cortez, 1992.

BARBIERI, C.; BITTAR, A. F. Esporte Educacional: Uma Proposta Renovada. Recife: Universidade de Pernambuco/UPE-ESEF MEE/INDESP, 1996.

BAYER, C. O ensino dos desportos coletivos. Paris: Vigot, 1994.

BETTI, M. Por uma teoria da prática. Revista Motus Corporis. Rio de Janeiro, v.3, n.2, p.73-127, 1996.

BIANCO, M. Capacidades cognitivas nas modalidades esportivas coletivas. IN: DE ROSE JUNIOR, Dante. Modalidades esportivas coletivas. Rio de Janeiro: Guanabara Koogan, 2006.

BRACHT, V. Aprendizagem Social e Educação Física. Porto Alegre: Magister, 1992.

CALDAS, I. S. L.; SOUZA, F. T. C.; SOUGEY, E. B. Formação esportiva no handebol e métodos de ensino-aprendizagem-treinamento (E-A-T), IN: CALDAS, I. S. L. Treinando Handebol. Recife: Ed. Universitária da UFPE, 2014.

CORTEZ, J. A. A. Modalidades Esportivas Coletivas: O Futebol, IN: IN: DE ROSE JUNIOR, D. Modalidades esportivas coletivas. Rio de Janeiro: Guanabara Koogan, 2006.

COSTA, L. C. A; NASCIMENTO, J.V. O ensino da Técnica e da tática: novas abordagens metodológicas. Revista da Educação Física. Maringá, v.15, n.2, p. 49-56, 2. Sem. 2004.

DAOLIO, J. Educação Física Escolar: em busca da pluralidade. Revista Paulista de Educação

Ensino do Esporte na Escola

Física. São Paulo, supl.2, p.40-42, 1996.

DE ROSE JUNIOR, D. Iniciação nas modalidades esportivas coletivas: a importância da dimensão tática. Revista Mackenzie de Educação Física e Esporte. v. 4, n. 4, p. 71-93, 2005.

DE ROSE JUNIOR, D; SILVA, T. A. F. As Modalidades Esportivas Coletivas (MEC): história e caracterização, IN: DE ROSE JUNIOR, D. Modalidades esportivas coletivas. Rio de Janeiro: Guanabara Koogan, 2006.

FREIRE, J. B. Educação de Corpo Inteiro: teoria e prática da Educação Física. São Paulo: Scipione, 1994.

GARGANTA, J. Estratégia e Táctica nos Jogos Desportivos Colectivos. In: OLIVEIRA, J.; TAVARES, F. Estratégia e Táctica nos Jogos Desportivos Colectivos. Universidade do Porto, 1996.

GARGANTA, J. Para uma teoria dos jogos desportivos coletivos. In: GRAÇA, A.; OLIVEIRA, J. O Ensino dos jogos desportivos. Porto: Rainho \& Neves, p. 11-25 1998.

GARGANTA, J. O treino da táctica e da estratégia nos jogos desportivos. In: GARGANTA, J. (Ed.). Horizonte e órbitas no treino dos jogos desportivos. Porto: Converge Artes Gráficas, p. 51-61, 2000.

GRAÇA, A.; MESQUITA, I. A investigação sobre os modelos de ensino dos jogos desportivos. Revista do Porto de Ciências do Desporto, v. 7, n. 3, p. 401-421, 2007.

GRECO, P. J. Sistematização do processo de ensino-aprendizagem-treinamento tático nos jogos esportivos coletivos. In: GRECO, P. J.; SAMULSKI, D. M.; GARCIA, E. S.; SZMUCHROWSKI, L. Temas atuais em Educação Física e esportes II. Belo Horizonte: Health, p. 44-56, 1997. 
GRECO, P. J. Iniciação esportiva universal: metodologia da iniciação esportiva na escola e no clube. Belo Horizonte, Ed. UFMG, 1998.

GRECO, P. J. Iniciação esportiva universal: da aprendizagem motora ao treinamento técnico. Belo Horizonte, Ed. UFMG, 2007 (2ª reimpressão).

GRECO, P. J. Organização e desenvolvimento pedagógico do esporte no programa segundo tempo. In: OLIVEIRA, A.A.B.; PERIM, G.L. Fundamentos pedagógicos do programa segundo tempo: da reflexão à prática. Maringá: Eduem, 2009.

GRECO, P. J.; SOARES, V. O. V. A análise da técnica-tática nos esportes coletivos: "por que", "o quê" e "como". Revista Mackenzie de Educação Física e Esportes. v. 9, n. 2, p. 3-11, 2010.

KUNZ, E. Transformação didático-pedagógica do esporte. ljuí. Ed: Unijuí, 2004.

MESQUITA, I.; GRAÇA, A. Modelos de Ensino dos jogos desportivos. IN: TANI, G.; BENTO, J. O.; PETERSEN, R. D. S. Pedagogia do desporto. Rio de Janeiro: Guanabara Koogan, 2006.

PAES, R. R. Pedagogia do esporte: contextos, evolução e perspectivas. Revista Brasileira de Educação Física e Esporte, São Paulo, v. 20, n. 5, p. 171, set. 2006.

REVERDITO, R. S.; SCAGLIA, A. J.; MONTANGNER, P. C. Pedagogia do esporte - aspectos conceituais da competição e estudos aplicados. São Paulo: Phorte Editora, 2013.

RODRIGUES, H. A.; DARIDO, S. C. A Técnica Esportiva em Aulas de Educação Física: um olhar sobre as tendências sócio-culturais. Porto Alegre, v. 14, n. 02, p. 139-154, 2008.

RONCHI, Â. M. A transformação didático-pedagógica do esporte na Educação Física Escolar. (monografia). Criciúma, 2010.

SADI, R. S. Pedagogia do esporte: descobrindo novos caminhos. São Paulo: Ícone, 2010.

\section{Ensino do Esporte na Escola}

SADI, R. S. et al. Ensino de esportes por meio de jogos: desenvolvimento e aplicações. Pensar a Prática. v. 11, n. 1, p. 17-26, 2008.

SCAGLIA, A. J.; REVERDITO, R. S. Pedagogia do esporte: jogos coletivos de invasão. São Paulo: Phorte, 2009.

SEABRA, F.; LAMAS, L. Estratégia, tática e técnica nas modalidades esportivas coletivas: conceitos e aplicações. IN: DE ROSE JUNIOR, D. Modalidades esportivas coletivas. Rio de Janeiro: Guanabara Koogan, 2006.

SIMÕES, A. C. Modalidades esportivas coletivas: o handebol. IN: DE ROSE JUNIOR. Modalidades esportivas coletivas. Rio de Janeiro: Guanabara Koogan, 2006.

TANI, G.; CORRÊA, U. C. Esportes coletivos: alguns desafios quando abordados sob uma visão sistêmica, IN: DE ROSE JUNIOR, D. Modalidades esportivas coletivas. Rio de Janeiro: Guanabara Koogan, 2006.

THOMAS, J. R. Métodos de Pesquisa em atividade física. 5. Ed. - Porto Alegre: Artmed, 2007. 